\title{
A NDIR Mid-Infrared Methane Sensor with a Compact Pentahedron Gas-Cell
}

\author{
Weilin Ye ${ }^{1}\left(\mathbb{D}\right.$, Zihan Tu $^{1}{ }^{1}$, Xupeng Xiao ${ }^{1}$, Alessandro Simeone ${ }^{1}{ }^{(\mathbb{O}}$, Jingwen Yan ${ }^{1}$, Tao $\mathrm{Wu}^{1}{ }^{1}$, \\ Fupei $\mathrm{Wu}^{1, * \mathbb{D}}$, Chuantao Zheng ${ }^{2, *}$ and Frank K. Tittel ${ }^{3} \mathbb{D}$ \\ 1 Key Laboratory of Intelligent Manufacturing Technology, Ministry of Education, College of Engineering, \\ Shantou University, 243 Daxue Road, Shantou 515063, China; wlye@stu.edu.cn (W.Y.); \\ 18zhtu@stu.edu.cn (Z.T.); 19xpxiao@stu.edu.cn (X.X.); simeone@stu.edu.cn (A.S.); jwyan@stu.edu.cn (J.Y.); \\ taowu@stu.edu.cn (T.W.) \\ 2 State Key Laboratory of Integrated Optoelectronics, College of Electronic Science and Engineering, \\ Jilin University, 2699 Qianjin Street, Changchun 130012, China \\ 3 Department of Electrical and Computer Engineering, Rice University, 6100 Main Street, Houston, TX 77005, \\ USA; fkt@rice.edu \\ * Correspondence: fpwu@stu.edu.cn (F.W.); zhengchuantao@jlu.edu.cn (C.Z.)
}

Received: 26 August 2020; Accepted: 18 September 2020; Published: 23 September 2020

\begin{abstract}
In order to improve the performance of the large divergence angle mid-infrared source in gas sensing, this paper aims at developing a methane $\left(\mathrm{CH}_{4}\right)$ sensor with non-dispersive infrared (NDIR) technology using a compact pentahedron gas-cell. A paraboloid concentrator, two biconvex lenses and five planar mirrors were used to set up the pentahedron structure. The gas cell is endowed with a $170 \mathrm{~mm}$ optical path length with a volume of $19.8 \mathrm{~mL}$. The mathematical model of the cross-section and the three-dimension spiral structure of the pentahedron gas-cell were established. The gas-cell was integrated with a mid-infrared light source and a detector as the optical part of the sensor. Concerning the electrical part, a STM32F429 was employed as a microcontroller to generate the driving signal for the IR source, and the signal from the detector was sampled by an analog-to-digital converter. A static volumetric method was employed for the experimental setup, and 20 different concentration $\mathrm{CH}_{4}$ samples were prepared to study the sensor's evaluation, which revealed a $1 \sigma$ detection limit of 2.96 parts-per-million (ppm) with a 43 s averaging time.
\end{abstract}

Keywords: infrared spectroscopy; mid-infrared sensor; NDIR; pentahedron gas-cell

\section{Introduction}

Methane $\left(\mathrm{CH}_{4}\right)$ is one of the simplest organic matters and is widely available in nature. It is a by-product of coal mines and can be considered as one of the most important greenhouse gases [1-5]. Therefore, $\mathrm{CH}_{4}$ detection is crucial in both industrial and in environmental scopes [3]. Numerous techniques have been successfully used in $\mathrm{CH}_{4}$ detection, such as tunable diode laser absorption spectroscopy (TDLAS) [6-8], quartz-enhanced photoacoustic spectroscopy (QEPAS) [9-11], and cavity enhanced absorption spectroscopy (CEAS) [12-14]. These kinds of $\mathrm{CH}_{4}$ sensors target very low detection limits (DL) at parts-per-billion ( $\mathrm{ppb}$ ) or even parts-per-trillion (ppt) levels. However, to achieve high accuracy and low DL, expensive lasers (tens of thousands of US dollars) are required, which makes these kinds of sensors unsuitable for wide industrial production or ordinary breath monitoring. The advantages of semiconductor gas sensors, specifically resistance and electrochemical types, consist of a small sizes (millimeters) and a low detection limits (ppb level); therefore, wide literature is available on such technology [15-17]. However, most of the available units are laboratory products and not yet commercialized, representing a boundary for the mass production and its related marketing. 
Incandescent lamp is one kind of mid-infrared source which has been demonstrated to be successfully employed in gas detectors based on infrared absorption due to its small size and low cost (a few US dollars) [18,19]. Non-dispersive infrared (NDIR) is a proper method for this kind of sensor [20-22]. However, due to the large divergence angle, such a kind of source cannot be condensed into the multi-pass gas cell for hundreds of reflections without mode overlap. Therefore, the design of a gas cell with small size and long optical path represents a challenge as regards the incandescent lamp within the infrared absorption sensor. In this paper, a paraboloid concentrator, two biconvex lenses and five planar mirrors were used to design the pentahedron gas-cell structure. $\mathrm{A} \mathrm{CH}_{4}$ sensor was integrated with this gas cell and the achieved detection limit could reach up to sub-ppm level.

\section{Pentahedron Gas-Cell Structure}

The selected light source was an IRL715, which is a kind of incandescent lamp widely used in NDIR sensor applications. The divergence angle of the IRL715 is $\sim 360^{\circ}$. To increase the optical length and reduce the gas-cell volume, a paraboloid concentrator was employed to collect the divergent light and two biconvex lenses were placed at the in- and out-let gas cells. For getting parallel light, five planar mirrors were setup with a pentahedron gas-cell for increasing the optical path.

\subsection{Paraboloid Concentrator}

To focus the divergence light from the IRL715, a paraboloid concentrator was designed according to the mathematical model shown in Figure $1 \mathrm{a}$. The focus of the parabola was $\mathrm{O}(0,3,0)$, the focal length was $0.66 \mathrm{~mm}$, the $\mathrm{OA}$ and $\mathrm{OB}$ distances were set to $6.5 \mathrm{~mm}$, and the thickness was $0.5 \mathrm{~mm}$. The outlet angle can be calculated as per Equation (1):

$$
\angle A O B=2 \times \arctan \left(\frac{y_{A}}{x_{A}-x_{o}}\right)=48.502^{\circ}
$$

where $y_{A}$ and $x_{A}$ are, respectively, the $y$ and $x$ axis coordinates of point $A$.

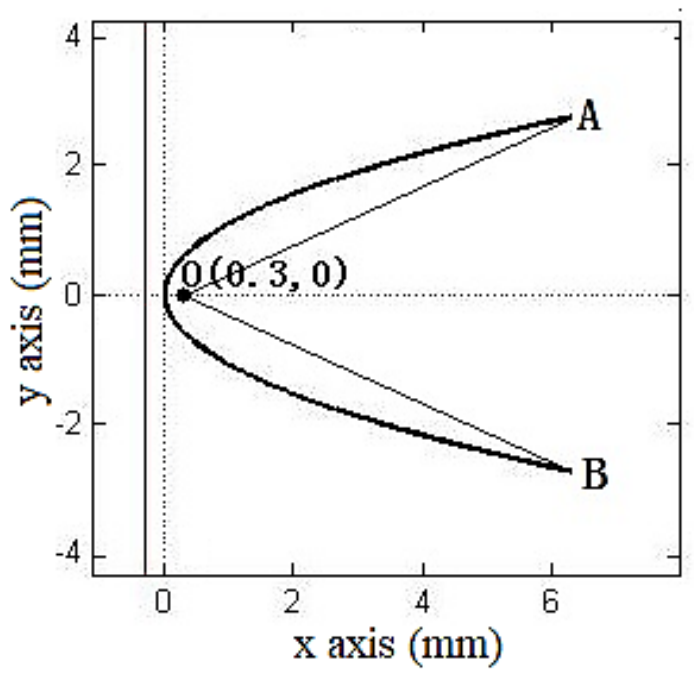

(a)

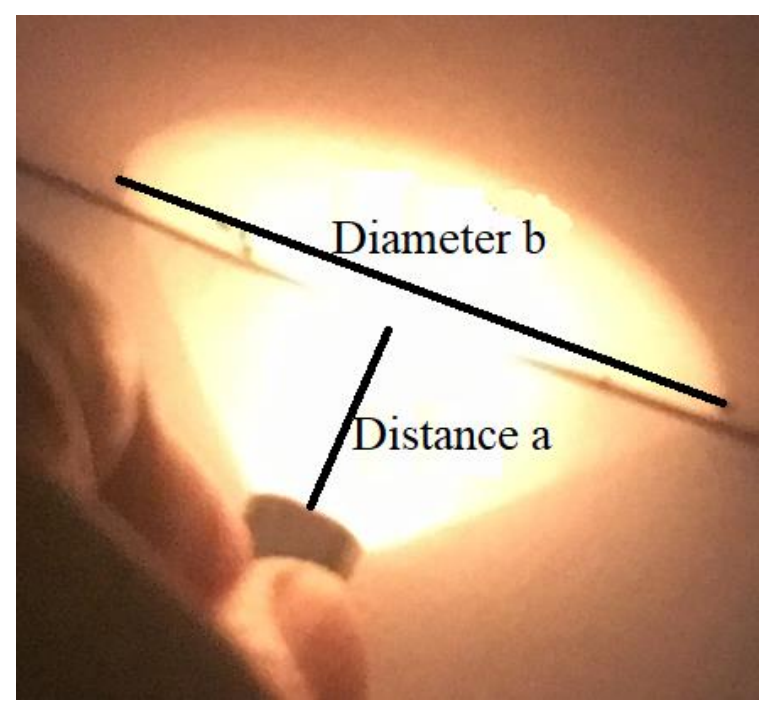

(b)

Figure 1. (a) The mathematical model and (b) experimental tests of paraboloid concentrator.

The experiment was carried out to verify the design, which is shown as Figure $1 \mathrm{~b}$. To calculate the divergence angle, experimental tests under different diameters were carried out, the distance $a$ and diameter $b$ of the spots were recorded and are reported in Table 1. 
Table 1. Light spot divergence angle test records.

\begin{tabular}{cc}
\hline Distance $\boldsymbol{a}(\mathbf{m m})$ & Diameter $\boldsymbol{b}(\mathbf{m m})$ \\
\hline 5 & 21.5 \\
10 & 31 \\
20 & 49.5 \\
30 & 68.5 \\
40 & 87.1 \\
60 & 12.65 \\
\hline
\end{tabular}

According to the triangle similarity, the divergence angle can be calculated by Equation (2):

$$
\alpha=2 \arctan \left(\frac{b_{2}-b_{1}}{a_{2}-a_{1}}\right)
$$

where $a$ and $b$ can be selected from Table 1 . The calculated average divergence angle $\alpha$ was $43.414^{\circ}$ and the error to the theoretical calculation by Equation (1) was only 10\%.

\subsection{Pentahedron Structure}

To parallel the beam, a convex lens was employed at the outlet of the output beam from paraboloid concentrator, and to converge the beam, another convex lens was used before the detector. The optical simulation is shown in Figure 2.

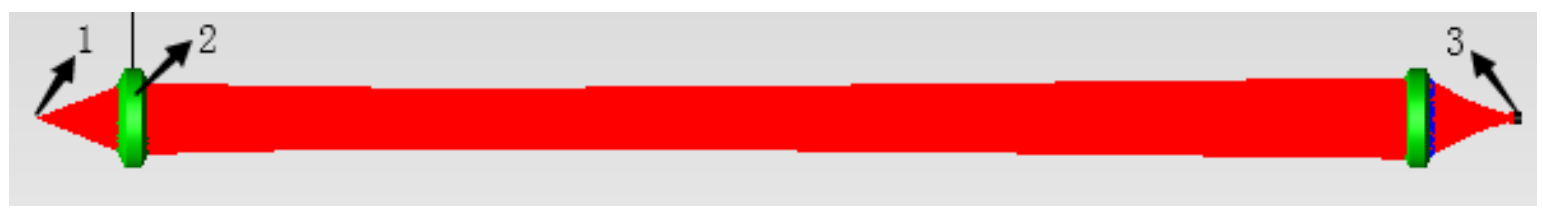

Figure 2. Optical simulation of the two convex lenses, where 1 is the output beam from the paraboloid concentrator, 2 is the convex lens and 3 is the detector.

With the aim of reducing the size, shown in Figure 2, five planar mirrors were added in order to build a small-size gas cell. The cross-section mathematical model is shown in Figure 3a and the three-dimensional spiral structure is shown in Figure $3 b$. E1 is the center of both convex lenses-the distances between the lens to the source and the lens to the detector are both $12 \mathrm{~mm}$. $\mathrm{AB}, \mathrm{BC}, \mathrm{CD}$ and $\mathrm{DE}$ are planar mirrors with diameters of $\sim 9.7 \mathrm{~mm}$, which is consistent with the diameter of the parallel beam.

In order to avoid overlapping issues in the spiral optical path, the lenses should be placed at a tilt angle $\beta$, which can be calculated by Equation (3):

$$
\beta \geq \arctan \left(\frac{D_{\text {path }}}{D_{\text {beam }}}\right)
$$

where $D_{\text {path }}$ is the optical path under one plane and $D_{\text {beam }}$ is the diameter of the beam. According to Equation (3), $\beta$ was chosen to be $10.2^{\circ}$, and the fifth mirror was placed between two convex lenses for increasing the optical path. According to the mathematical model implementation, the optical path from the source to the detector can reach $170 \mathrm{~mm}$ with a volume of $19.8 \mathrm{~mL}$. 


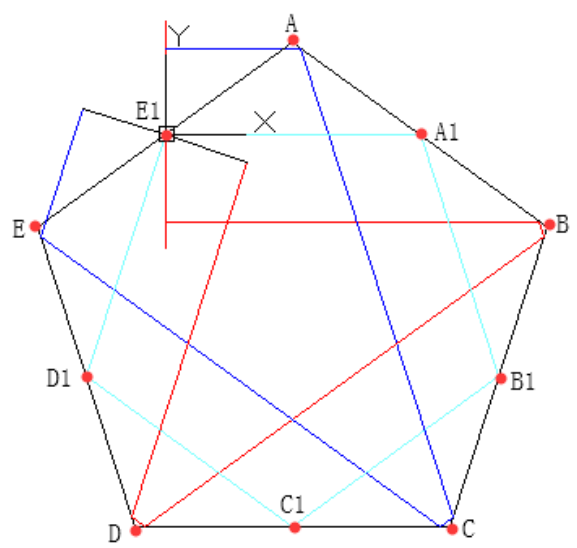

(a)

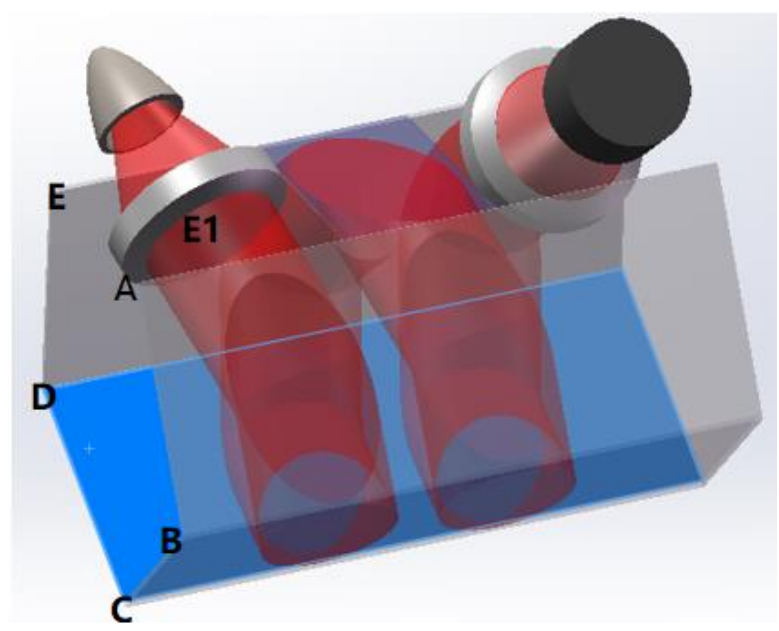

(b)

Figure 3. (a) Mathematical model of cross-section and (b) three-dimensional spiral structure of the pentahedron gas-cell.

\section{NDIR Sensor Configuration}

The NDIR $\mathrm{CH}_{4}$ sensor consists of optical parts and electrical parts. The core of optical part is the pentahedron gas-cell-the electrical part contains the hardware connection and software program.

\subsection{Sensor Architecture}

The schematic diagram of the NDIR $\mathrm{CH}_{4}$ sensor is depicted in Figure $4 \mathrm{a}$, including electrical and optical part. A photo is shown in Figure $4 \mathrm{~b}$ with the dimensions of $18(L) \times 18(W) \times 15(H) \mathrm{cm}$. The pentahedron gas cell was integrated in the optical part of the sensor. In the electrical part, a STM32F429 (STMicroelectronics, Geneva, Switzerland) was employed as the MCU (Microcontroller Unit) of the whole system, which generated a $4 \mathrm{~Hz}$ square-wave to drive the IR source (IRL715, Perkin Elmer) and collected output signals from the detector (PYS3228TCG5.2, Excelitas, USA) to the analog-to-digital converter (ADC, ADS1113, Texas Instruments, USA).

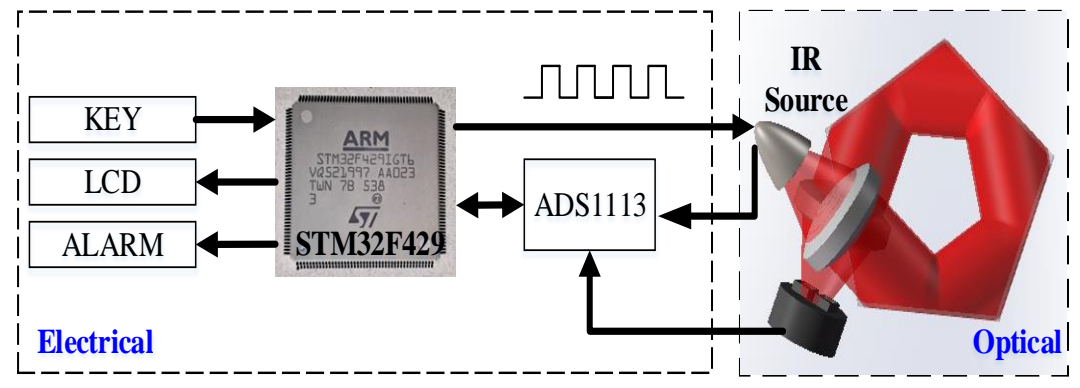

(a)

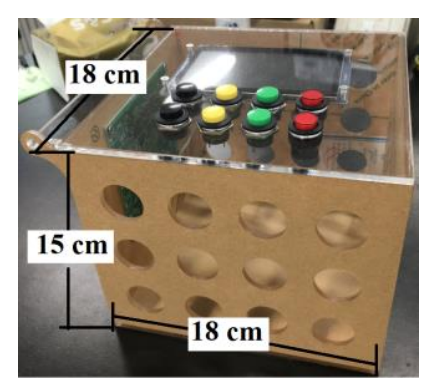

(b)

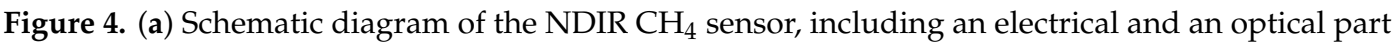
and (b) photo of the sensor.

\subsection{Hardware Design}

To get the stable optical power, a constant current driver circuit was designed with a MOSFET as a switch and an amplifier as a feedback controller-the circuit board is shown in Figure 5. This board can generate a constant current for IRL715 with a power of $0.5 \mathrm{~W}$. For testing the stability of this circuit, four currents of $30 \mathrm{~mA}, 50 \mathrm{~mA}, 70 \mathrm{~mA}$ and $90 \mathrm{~mA}$ were set and tested for $1 \mathrm{~h}$. From Figure 6 , the fluctuation of the current is $\pm 0.083 \mathrm{~mA}$. 


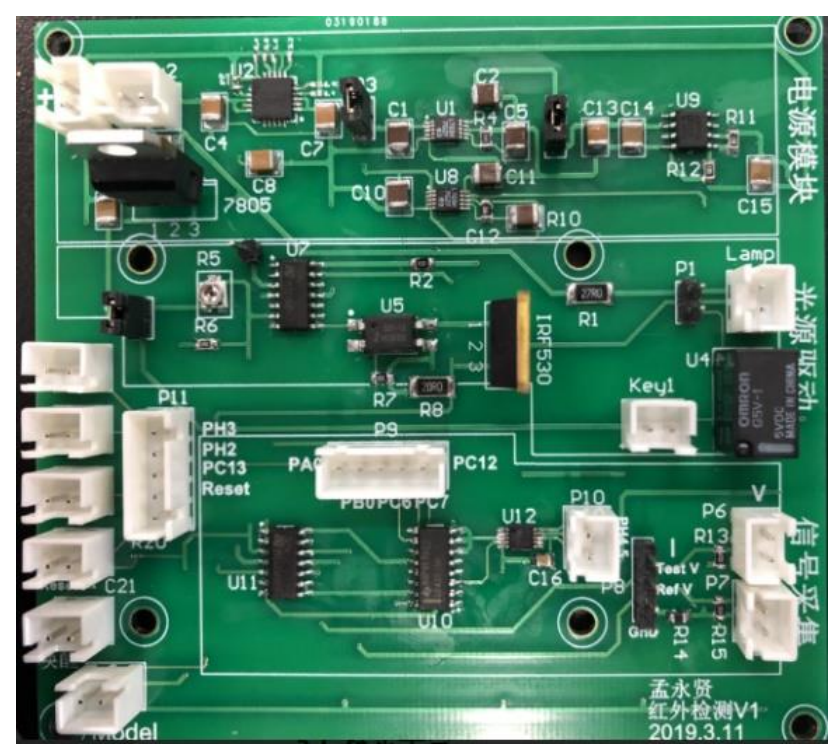

Figure 5. Photo of circuit board.
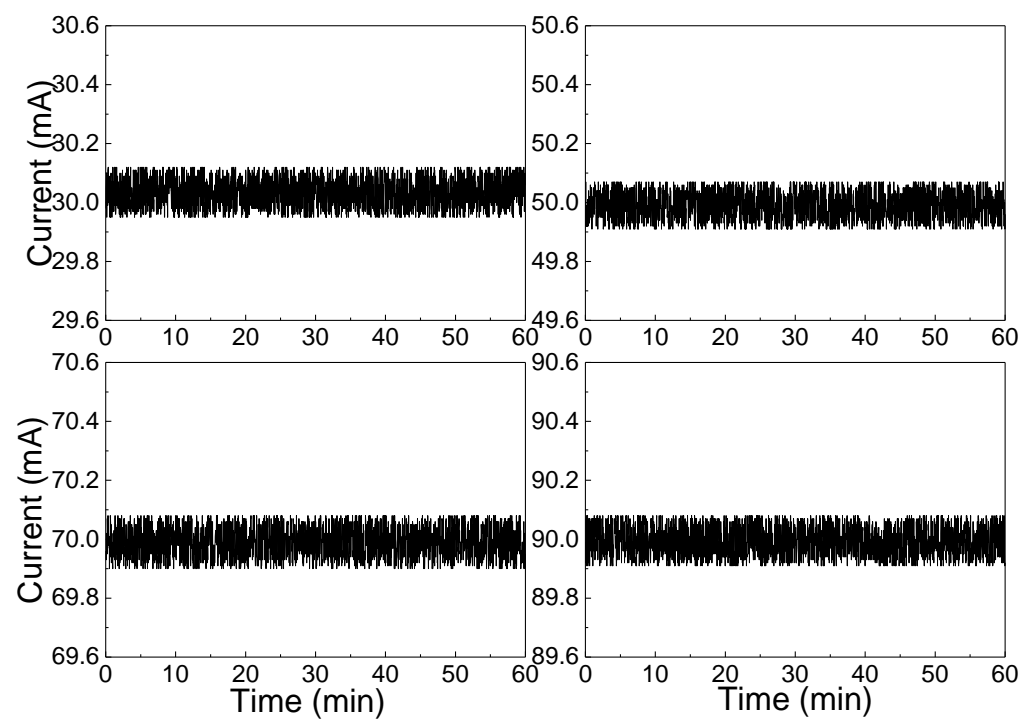

Figure 6. Flow chart of main detection procedure of STM32 processor.

The detector is shown in Figure 7a, which is a pyroelectric sensor with two channels of $3.31 \mathrm{um}$ and $4.0 \mathrm{um}$. The signal output $\left(\mathrm{U}_{\text {sig }}\right)$ from the channel with $3.3 \mathrm{um}$ optical filter was absorbed by $\mathrm{CH}_{4}$, which can be used for $\mathrm{CH}_{4}$ concentration detection. The one from the channel with 4.0 um optical filter window $\left(\mathrm{U}_{\text {ref }}\right)$ without any absorption, which can be used as the reference channel for noise suppression. There are four pins on the detector, which were connected to the power, ground and the $\mathrm{U}_{\text {sig }}$ and $\mathrm{U}_{\text {re. }}$. The electrical connection is shown in Figure $7 \mathrm{~b}$ - two $47 \mathrm{~K}$ resistances were employed for impedance matching and a magnetic bead (MB) was selected for suppressing the electrical influence from power supply. 


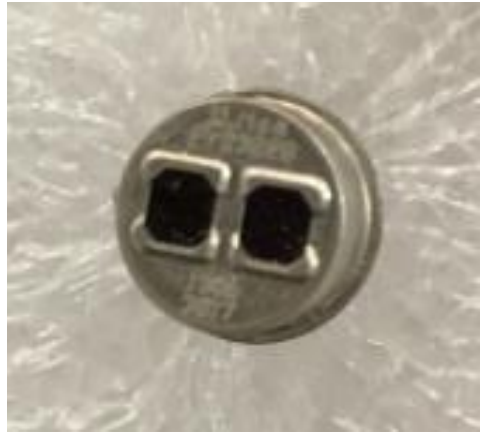

(a)

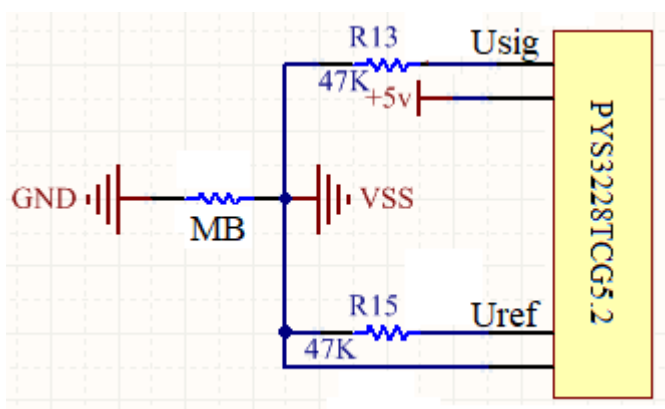

(b)

Figure 7. (a) The mathematical model and (b) experimental tests of paraboloid concentrator.

In addition, the concentration threshold can be set through a keyboard. The real-time concentration can be shown on an LCD and stored in a secure digital (SD) card. Once the detected $\mathrm{CH}_{4}$ concentration result is higher than the set threshold value, an acousto-optic alarm is be triggered.

\subsection{Signal Acquisition and Processing}

The flow chart of the sensor's signal acquisition and processing is depicted in Figure 8. In order to get a stable signal from the sensor, a constant current to the IR source is a primary key. A negative feedback programmable constant current was developed for this sensor. The ADS1113 sampled the real-time current signal from the IR source in a continuous conversion mode at the sampling rate of 475 samples per second (SPS). The sampled current was compared with the preset maximum-minimum current bounds and adjusted in real-time. If the current value was higher than the upper limit for more than $3 \mathrm{~s}$, the hardware protection circuit will be triggered.

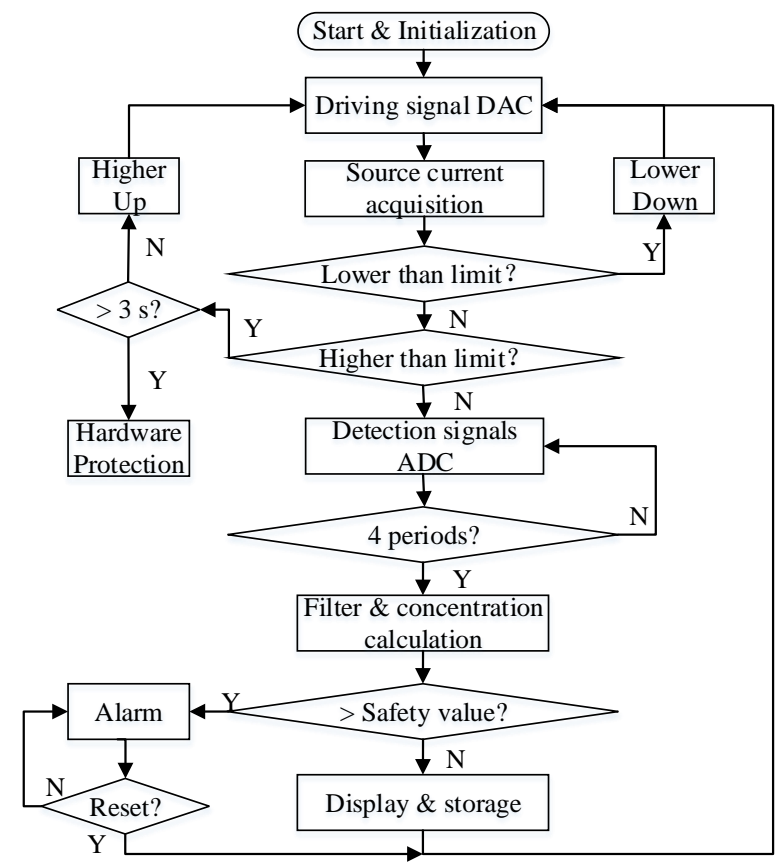

Figure 8. Flow chart of the sensor's signal acquisition and processing.

The analog signal from the detector was converted by the ADS1113 to a digital signal and sent to the MCU. A program of mean filter was compiled to suppress the noise. The concentration was calculated and compared to the threshold, once the value exceeded the safety value, the acousto-optic 
alarm was triggered and set to wait for reset. If the concentration was below the threshold, it would be displayed on the LCD and stored in the SD card.

\section{Experimental Tests and Results}

\subsection{Expeirmental Setup}

An air-tight chamber made of acrylic plate was designed with a size of $40 \mathrm{~cm} \times 40 \mathrm{~cm} \times 30 \mathrm{~cm}$ and a volume of 48 liters, as shown in Figure 9. A 1/4 inch $(6.35 \mathrm{~mm})$ three-way ferrule ball valve was connected with the M12 $\times 1.25$ thread to ensure the air tightness. The valve had two inlets-one was connected with a pure $\mathrm{N}_{2}$ cylinder and the other was connected with a $99.999 \% \mathrm{CH}_{4}$ cylinder. Based on ISO 6144: 2003 [23], the concentration in the chamber can be calculated as per Equation (4):

$$
\phi(x)=\frac{p_{1} \times V_{x g}}{p_{2} \times V_{c g}+p_{1} \times V_{x g}}
$$

where $\phi(x)$ is the target concentration of $\mathrm{CH}_{4}, p_{1}$ and $p_{2}$ are the pressure values inside the chamber, respectively, before and after the distribution, $V_{c g}$ is the volume of the chamber and $V_{x g}$ is the volume of the injected gas. According to Equation (4), 20 different concentrations $(C)$ with volumes $(V)$ for calibration were calculated and are listed in Table 2.

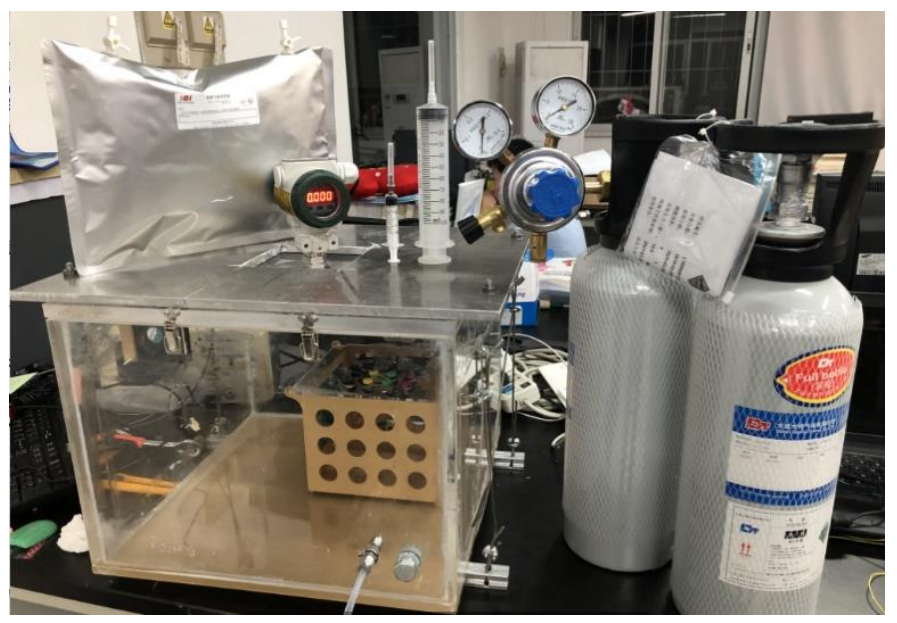

Figure 9. Photo of the air-tight chamber.

Table 2. The calculated $\mathrm{CH}_{4}$ concentration values and volumes for calibration.

\begin{tabular}{cccccccccc}
\hline $\mathbf{C ~ ( \% )}$ & $\mathbf{V}(\mathbf{m L})$ & $\mathbf{C ~ ( \% )}$ & $\mathbf{V ~ ( m L )}$ & $\mathbf{C ~ ( \% )}$ & $\mathbf{V}(\mathbf{m L})$ & $\mathbf{C ~ ( \% )}$ & $\mathbf{V}(\mathbf{m L})$ & $\mathbf{C}(\%)$ & $\mathbf{V}(\mathbf{m L})$ \\
\hline 0.1 & 48.1 & 0.2 & 96.2 & 0.3 & 144.4 & 0.4 & 192.8 & 0.5 & 241.7 \\
0.6 & 289.7 & 0.7 & 339.7 & 0.8 & 387.1 & 0.9 & 435.9 & 1.0 & 484.8 \\
1.1 & 533.9 & 1.2 & 583.0 & 1.3 & 632.2 & 1.4 & 681.5 & 1.5 & 731.0 \\
1.6 & 780.5 & 1.7 & 830.1 & 1.8 & 880.0 & 1.9 & 929.7 & 2.0 & 979.6 \\
\hline
\end{tabular}

\subsection{Sensor Evaluation}

The sensor calibration was carried out by using 20 different $\mathrm{CH}_{4}$ concentration samples from Table 2, and the results are shown in Figure 10a. The voltage ratio between the two channels from the detector, signal $\left(U_{\text {sig }}\right)$ and reference $\left(U_{\text {ref }}\right)$, were used for noise suppression. The averaged values and fitting curve are shown in Figure 10b. The fitting curve indicates a good exponential relationship (R-square value: $99.79 \%$ ), which is consistent with the Lambert-Beer's Rule [24], expressed by Equation (5):

$$
\frac{U_{\text {sig }}}{U_{\text {ref }}}=1.11515+0.13069 \exp ^{\left(\frac{-C}{1.37711}\right)}
$$




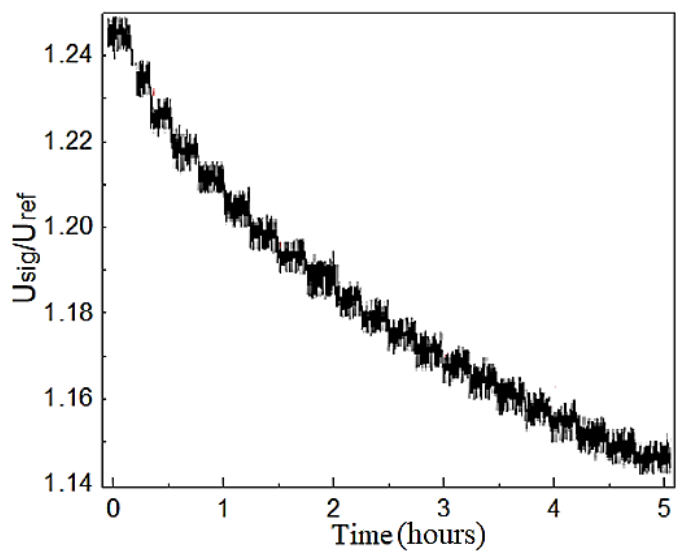

(a)

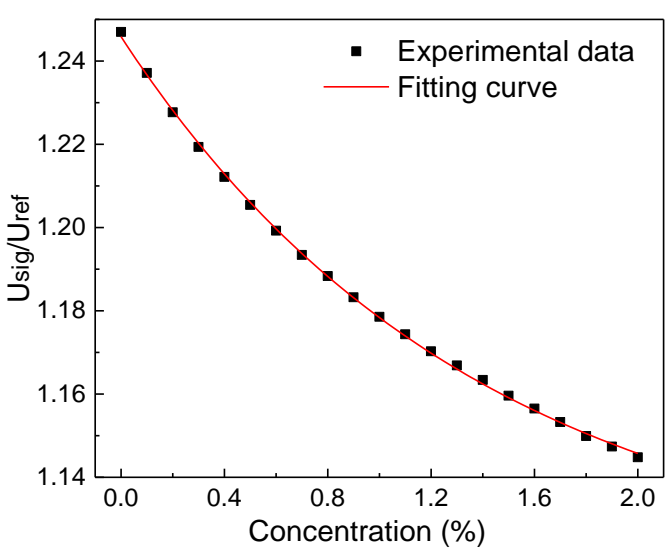

(b)

Figure 10. (a) The measured voltage ratio between the two channels from the detector versus calibration time $t$ for $20 \mathrm{CH}_{4}$ concentration levels. (b) Experimental data and fitting curve.

For evaluating the accuracy of the $\mathrm{CH}_{4}$ sensor, the error bar was employed to compare the measured and the standard concentration, as shown in Figure 11, where the fitting curve indicated a good linear relationship (R-square value: $99.95 \%$ ).

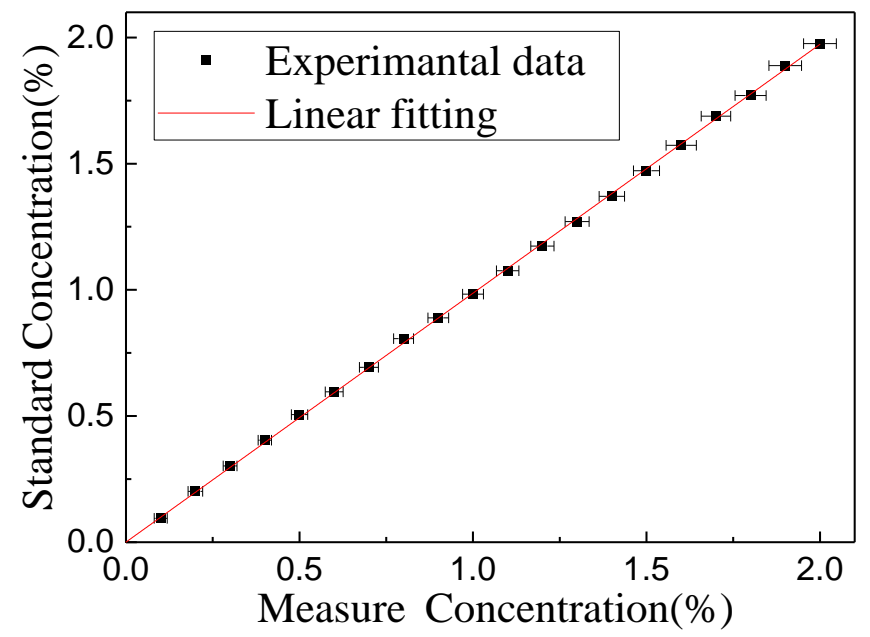

Figure 11. Fitting curve of the measured and standard concentration.

Measurement of a $\mathrm{CH}_{4}$ sample with $2 \%$ concentration over a period of $\sim 1 \mathrm{~h}$ was performed. Figure 12 shows the Allan variation, which is defined as Equation (6), which calculates one half of the averaging time of the squares of the differences between successive readings of the frequency deviation sampled over the sampling period [25]. The Allan variation is $~ 176.5$ parts-per-million (ppm) with a $1 \mathrm{~s}$ averaging time and an optimum averaging time of $43 \mathrm{~s}$, corresponding to a detection limit of $2.96 \mathrm{ppm}$.

$$
\sigma_{\mathrm{y}}^{2}(\tau)=\frac{1}{2 \tau^{2}}\left[\left(x_{n+2}-2 x_{n+1}+x_{n}\right)^{2}\right]
$$

where $\tau$ is the averaging time, $x_{n}$ is the measurement result at time $t$. 


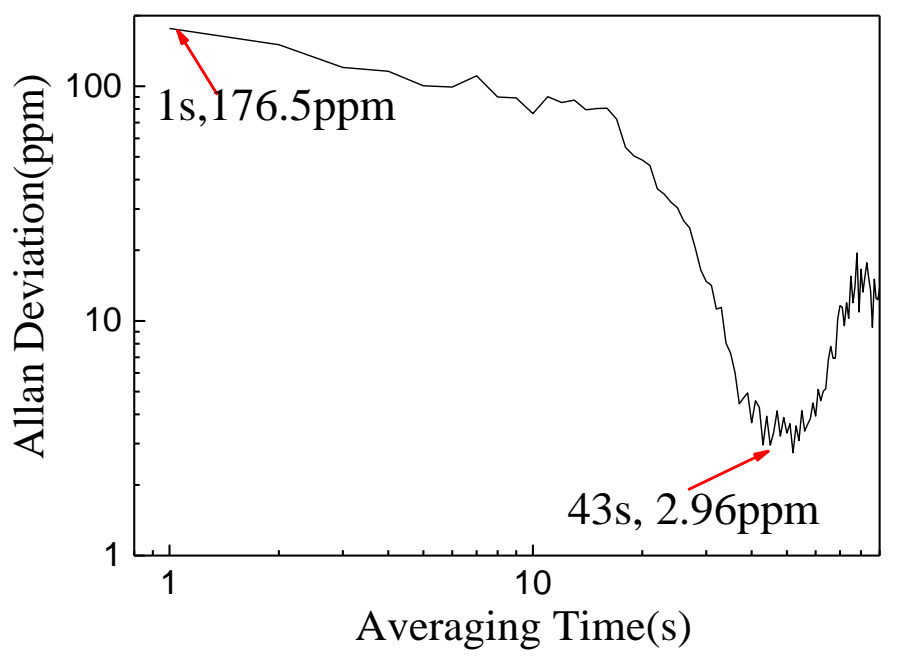

Figure 12. Allan variation plot as a function of averaging time.

\section{Conclusions}

A portable $\mathrm{CH}_{4}$ sensor using a compact pentahedron gas-cell, based on NDIR technology, was demonstrated. The gas-cell with a paraboloid concentrator, two biconvex lenses and five planar mirrors was realized with a $170 \mathrm{~mm}$ optical path length and a 19.8-mL volume. Statistic distribution was used in the $\mathrm{CH}_{4}$ measurement for evaluating the sensor's performance and 20 samples with different concentration levels were prepared for calibration. An Allan variation analysis yielded a detection sensitivity of $2.96 \mathrm{ppm}$ with a $43 \mathrm{~s}$ averaging time.

Author Contributions: Writing and editing, W.Y., A.S.; validation, Z.T.; experiments, X.X.; supervision, J.Y., T.W. and F.W.; review C.Z. and F.K.T. All authors have read and agreed to the published version of the manuscript.

Funding: This research was funded by the Science and Technology Planning Project of Guangdong Province, China (Nos. 2017A020216011 and 180914204960289), the National Science Foundation of Guangdong, China (No. 2018A0303130188) and the Open Fund of the State Key Laboratory of Integrated Optoelectronics, China (No. IOSKL2018KF09). Dr. Zheng would like to acknowledge the support from the National Natural Science Foundation of China (Nos. 61775079, 61627823, 61960206004), and the Key Science and Technology R\&D program of Jilin Province, China (Nos. 20180201046GX, 20190101016JH, 20200401059GX).

Conflicts of Interest: The authors declare no conflict of interest.

\section{References}

1. Ye, W.; Zhou, B.; Tu, Z.; Xiao, X.; Yan, J.; Wu, T.; Wu, F.; Zheng, C.; Tittel, K.F. Leakage source location based on Gaussian plume diffusion model using a near-infrared sensor. Infrared Phys. Technol. 2020, 109, 103411. [CrossRef]

2. Brandt, A.R.; Heath, G.A.; Cooley, D. Methane leaks from natural gas systems follow extreme distributions. Environ. Sci. Technol. 2016, 50, 12512-12520. [CrossRef] [PubMed]

3. Bamberger, I.; Stieger, J.; Buchmann, N.; Eugster, W. Spatial variability of methane: Attributing atmospheric concentrations to emissions. Environ. Pollut. 2014, 190, 65-74. [CrossRef] [PubMed]

4. Zheng, H.; Liu, Y.; Lin, H.; Kan, R.; Patimisco, P.; Sampaolo, A.; Giglio, M.; Zhu, W.; Yu, J.; Tittle, K.F. Sub-ppb-level $\mathrm{CH} 4$ detection by exploiting a low-noise differential photoacoustic resonator with a room-temperature interband cascade laser. Opt. Express 2020, 28, 19446. [CrossRef] [PubMed]

5. Mahbub, P.; Noori, A.; Parry, J.S.; Davis, J.; Lucieer, A.; Macka, M. Continuous and real-time indoor and outdoor methane sensing with portable optical sensor using rapidly pulsed IR LEDs. Talanta 2020, 218, 121144. [CrossRef] [PubMed]

6. Zheng, C.; Ye, W.; Sanchez, P.N.; Li, C.; Dong, L.; Wang, Y.; Griffin, J.R.; Tittel, K.F. Development and field deployment of a mid-infrared methane sensor without pressure control using interband cascade laser absorption spectroscopy. Sens. Actuators B Chem. 2017, 244, 365-372. [CrossRef] 
7. Ye, W.; Zheng, C.; Sanchez, P.N.; Girija, V.A.; He, Q.; Zheng, H.; Griffin, J.R.; Tittel, K.F. Thermal effects of an ICL-based mid-infrared $\mathrm{CH} 4$ sensor within a wide atmospheric temperature range. Infrared Phys. Technol. 2018, 89, 299-303. [CrossRef]

8. Avetisov, V.; Bjoroey, O.; Wang, J.; Geiser, P.; Paulsen, K. Hydrogen Sensor Based on Tunable Diode Laser Absorption Spectroscopy. Sensors 2019, 19, 5313. [CrossRef] [PubMed]

9. Wei, T.; Wu, H.; Dong, L.; Tittel, K.F. Acoustic Detection Module Design of a Quartz-Enhanced Photoacoustic Sensor. Sensors 2019, 19, 1093. [CrossRef] [PubMed]

10. Tomasz, S.; Piotr, A. A High Sensitivity Preamplifier for Quartz Tuning Forks in QEPAS (Quartz Enhanced PhotoAcoustic Spectroscopy) Applications. Sensors 2017, 17, 2528.

11. Christensen, J.B.; Hogstedt, L.; Friis, S.M.M.; Lai, J.; Chou, M.; Balslev, H.D.; Petersen, J.C.; Lassen, M. Intrinsic Spectral Resolution Limitations of QEPAS Sensors for Fast and Broad Wavelength Tuning. Sensors 2020, 20, 4725. [CrossRef] [PubMed]

12. Norbert, L.; Uwe, M.; Henrik, Z.; Glitsch, S.; Wiese, M.; Ropcke, J.; van Helden, J. RES-Q-Trace: A Mobile CEAS-Based Demonstrator for Multi-Component Trace Gas Detection in the MIR. Sensors 2018, 18, 2058.

13. He, Q.; Feng, Q.; Li, J. Long-Term Stable Online Acetylene Detection by a CEAS System with Suppression of Cavity Length Drift. Sensors 2019, 19, 508. [CrossRef] [PubMed]

14. Alquaity, A.B.S.; Utsav, K.C.; Popov, A.; Farooq, A. Detection of shock-heated hydrogen peroxide (H2O2) by off-axis cavity-enhanced absorption spectroscopy (OA-CEAS). Appl. Phys. B 2017, 123, 280. [CrossRef]

15. Tai, H.; Duan, Z.; He, Z.; Li, X.; Xu, J.; Liu, B.; Jiang, Y. Enhanced ammonia response of $\mathrm{Ti}_{3} \mathrm{C}_{2} \mathrm{~T}_{\mathrm{X}}$ nanosheets supported by $\mathrm{TiO}_{2}$ nanoparticles at room temperature. Sens. Actuators B Chem. 2019, 298, 126874. [CrossRef]

16. Chen, T.; Chang, S.; Hung, F.; Chang, S.; Hu, Z.; Chen, K. Simple Fabrication Process for 2D ZnO Nanowalls and Their Potential Application as a Methane Sensor. Sensors 2013, 13, 3941-3950. [CrossRef]

17. Tai, H.; Duan, Z.; Wang, Y.; Wang, S.; Jiang, Y. Paper-Based Sensors for Gas, Humidity, and Strain Detections: A Review. ACS Appl. Mater. Interfaces 2020, 12, 31037-31053. [CrossRef]

18. PerkinElmer Optoelectronics. IRL715, Product Data Infrared Sources. pp. 1-8. Available online: http: //www.hofoo.com.cn/uploadfiles/irl715.pdf (accessed on 15 December 2000).

19. Zhao, Z.; Liu, N.; Zhang, J.; Wang, Z.; Li, X.; Tian, E. Design of Non-Dispersed Infrared (NDIR) Methane Gas Sensor. Spectrosc. Spectr. Anal. 2011, 31, 570-573.

20. Liu, H.; Shi, Y.; Wang, T. Design of a six-gas NDIR gas sensor using an integrated optical gas chamber. Opt. Express 2020, 28, 11451. [CrossRef]

21. Hodgkinson, J.; Smith, R.; Ho, W.O.; Saffell, R.J.; Tatam, P.R. Non-dispersive infra-red (NDIR) measurement of carbon dioxide at $4.2 \mu \mathrm{m}$ in a compact and optically efficient sensor. Sens. Actuators B Chem. 2013, 186, 580-588. [CrossRef]

22. Vincent, T.A.; Gardner, J.W. A low cost MEMS based NDIR system for the monitoring of carbon dioxide in breath analysis at ppm levels. Sens. Actuators B Chem. 2016, 236, 954-964. [CrossRef]

23. ISO 6144:2003, Gas Analysis-Preparation of Calibration Gas Mixtures-Static Volumetric Method; ISO: Geneva, Switzerland. Available online: https://www.iso.org/standard/24666.html (accessed on 1 February 2003).

24. Mayerhofer, T.G.; Mutschke, H.; Popp, J. Employing Theories Far beyond Their Limits-The Case of the (Boguer-) Beer-Lambert Law. ChemPhysChem 2016, 17, 1948-1955. [CrossRef] [PubMed]

25. Allan, D.W. Statistics of Atomic Frequency Standards. Proc. IEEE 1966, 54, 221-230. [CrossRef]

(C) 2020 by the authors. Licensee MDPI, Basel, Switzerland. This article is an open access article distributed under the terms and conditions of the Creative Commons Attribution (CC BY) license (http://creativecommons.org/licenses/by/4.0/). 